\title{
SPEED CONTROL OF DC MOTOR ON LOAD USING FUZZY LOGIC CONTROLLER (A CASE STUDY OF EMERGENCY LUBE OIL PUMP MOTOR OF H25 HITACHI TURBINE GENERATOR)
}

\author{
I. I. Ekpoudom ${ }^{1,}{ }^{*}$, I. E. Archibong ${ }^{2}$ and U. T. Itaketo ${ }^{3}$

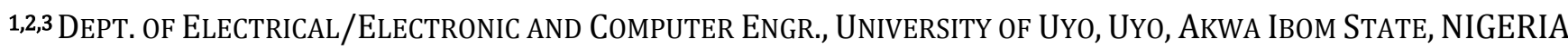 \\ E-mail addresses:1 highpointer7@yahoo.com, ${ }^{2}$ idoren2001@yahoo.com, ${ }^{3}$ engr1easy@yahoo.com
}

\begin{abstract}
This paper presents the development of a fuzzy logic controller for the driver DC motor in the lube oil system of the H25 Hitachi gas turbine generator. The turbine generator is required to run at an operating pressure of 1.5bar with the low and the high pressure trip points being 0.78 bar and 1.9 bar respectively. However, the driver DC motor speed drifted from the desired speed of 1450 revolutions per minutes (rpm) to as low as $1414 \mathrm{rpm}$. It is against this backdrop, that this project work was envisaged to design a controller capable of controlling the speed of the DC motor in order to achieve the desired speed rating of $1450 \mathrm{rpm}$. In modelling the motor, the transfer function method was used to develop a linear approximation to the actual motor. After computing the total inertia of the motor shaft, the motor model was simulated for the speed response in MATLAB and Simulink environment, and the response showed that the motor attained an actual maximum speed of $1414 \mathrm{rpm}$ at settling time of 0.3 seconds. Based on expert knowledge of the lube oil system, a fuzzy logic controller was designed and this resulted in the issuance of a control action to correct the actual speed of the motor from $1414 \mathrm{rpm}$ to the desired speed of $1450 \mathrm{rpm}$.
\end{abstract}

Keywords: dc motor, fuzzy logic controller, modelling, membership function, speed of response

\section{INTRODUCTION}

The need to control the motor speed is borne out of the necessity to achieve the desired vendor motor speed which has actually drifted overtime. The lube oil system pressure depends on the speed of driver motor. In gas turbine engines, the lubrication system is maintained at a predetermined pressure by the manufacturer and this pressure has acceptable limits. If the pressure falls outside the limits or the operating envelope, there could be serious impact on the performance and availability of the rotating parts of the gas turbine. Besides, severe pressure drop in the lube oil system of gas turbine generator can cause the Human Machine Interface (HMI) to shut down the turbine while it is on load [1].

Obviously, design shows that the discharge pressure of the lube oil pump is directly dependent on the speed of the driver motor. Hence, if the driver motor develops a fault that results in speed drop, there is a corresponding reduction in the discharge pressure.

Fuzzy Logic differs in concept and content from the traditional multivalued systems. Fuzzy logic systems make use of linguistic variable instead of numbers or crisp values [2]. Fuzzy logic controllers are widely used in various and varied control schemes and in most instances positioned in the forward path of a feedback control system in which the control output is compared with a reference, and if there is an offset, the controller takes action to minimize the error to as low as practicable [3].

\section{METHODOLOGY}

2.1 The Lube Oil System of the H25 Hitachi Gas Turbine System

The lube oil is stored in a large reservoir from where it is pumped to the bearings and control system by the main oil pump. In gas turbine engines, pressure circulating lubrication system is used and this is sometimes called forced-feed lubrication system. The lube system majorly consists of lube oil reservoir, main lube oil pump, auxiliary lube oil pump, emergency lube oil pump, pressure relief valve, bearing header pressure regulator, heater and lube oil filter. All these components work together to circulate oil throughout the entire turbine systems [1].

When the lubricating oil pressure gets too low turbines are stopped by a hydraulic trip. The safety philosophy requires an automatic dump valve to release oil from a trip cylinder to shut off the fuel supply whenever the lube oil pressure gets too low. A simplified schematic

* Corresponding author, tel: + 234-803-799-0505 
diagram of the turbine lube oil system is shown in Figure 1.

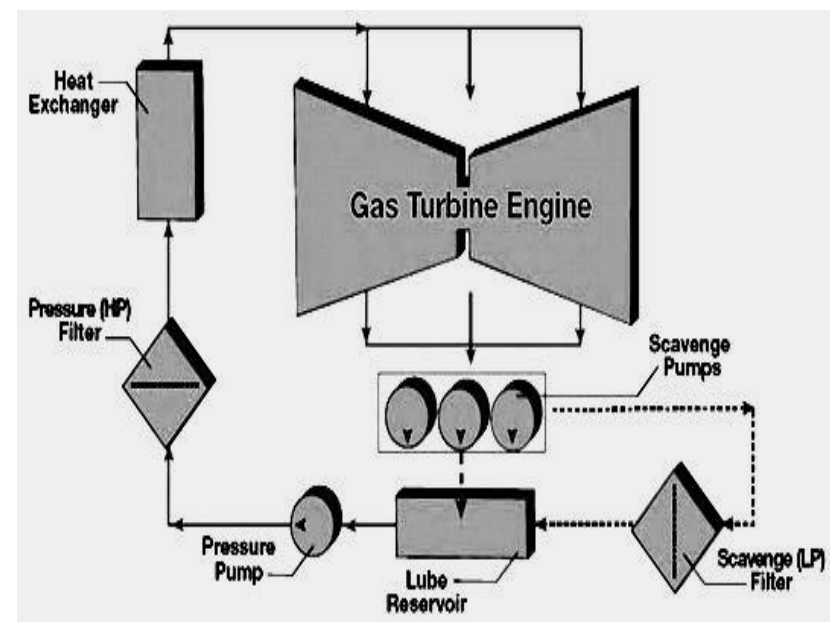

Figure 1: Simplified Diagram of the Gas Turbine Lubrication System, Source:[11]

\subsection{Mathematical Modelling of DC Motor}

There are basic sources of driving lubrication oil pump in gas turbines engines which include, pneumatic, hydraulic and electric. In this project case study, the lube oil pump is being driven electrically with the use of a DC drive motor. The DC motor converts direct current electrical power to mechanical power. A major fraction of the torque generated in the armature is available to drive the inertial load of the lube oil pump. In modelling the motor, the transfer function method was used to develop a linear approximation to the actual motor. Second-order effects such as hysteresis and voltage drop across the brushes were neglected [4]. The DC motor wiring diagram is given in Figure 2.

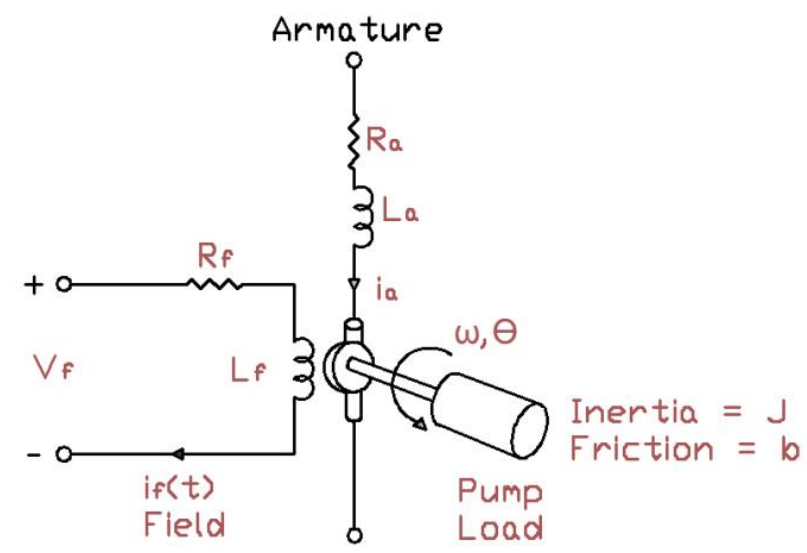

Figure 2: DC Motor wiring diagram [5].

\subsubsection{Electrical Characterization of the DC Motor}

The input voltage to the motor was applied to the field terminal. The field current is proportional to the magnetic flux of the air-gap that exists in the motor provided the field is remaining unsaturated and the expression is given as:

$$
\emptyset=K_{f} i_{f}
$$

There is a linear relationship between the torque developed by the motor, the air-gap flux and the armature current and is as follows:

$$
T_{m}=K_{1} \varnothing i_{a}(t)
$$

where, $\emptyset$ is magnetic flux in the air gap

Tm is motor torque and $i_{a}$ is armature current

Substituting equation (1) in (2), results in the expression below

$$
T_{m}=K_{1} K_{f} i_{f}(t) i_{a}(t)
$$

In this project work, the lube oil pump driver is a field current - controlled DC motor which is known to having substantial power amplification. In this type of DC motor, the armature current is kept constant while the field current is varied as the voltage input into the electrical circuit [6]. In Laplace transform notation, equation (3) becomes,

$$
T_{m}=\left(K_{1} K_{f} I_{a}\right) I_{f}(s)=K_{m} I_{f}(s)
$$

In (4), $i_{a}=I_{a}$ is a constant armature current, $K_{m}=\left(K_{1} K_{f} I_{a}\right)$ is defined as the motor constant. It is worth mentioning that the field current is related to the field voltage as in equation (5) [7]

$$
V_{f}=\left(R_{f}+L_{f} \frac{d}{d t}\right) i_{f}(t)
$$

Applying Laplace transform methods to equation 5, results in

$$
V_{f}(s)=\left(R_{f}+L_{f} s\right) I_{f}(s)
$$

\subsubsection{Mechanical Characterization of the DC Motor}

A greater portion of the torque developed by the motor was delivered and used to drive the lube pump load and the relation may be expressed as

$$
T_{m}=T_{p}+T_{d}
$$

In (7), $T_{p}$ is the torque requirement of the motor from the pump and $T_{d}$ is the disturbance torque, which is often negligible. However, it is advisable to consider the disturbance torque in systems subjected to external forces [8]. Assuming the lube-oil pump is directly coupled to the motor shaft as shown in figure 1, the total available load torque is written as:

$$
T_{p}=J \frac{d \omega(t)}{d t}+b \omega(t)
$$

where, $J$ is the total inertia of the pump impeller and motor rotor

$\omega(t)$ is the angular speed of the motor shaft and $b$ is the viscous friction coefficient. The total inertia that the motor shaft is subjected to is:

$$
J=J_{p}+J_{m}
$$

Where $J_{p}$ is the inertia of the pump impeller, $J_{m}$ is the inertia of the motor rotor.

Substituting equation (8) in (7), it follows that

$$
K_{m} i_{f}(t)=J \frac{d \omega(t)}{d t}+b \omega(t)+T_{d}
$$




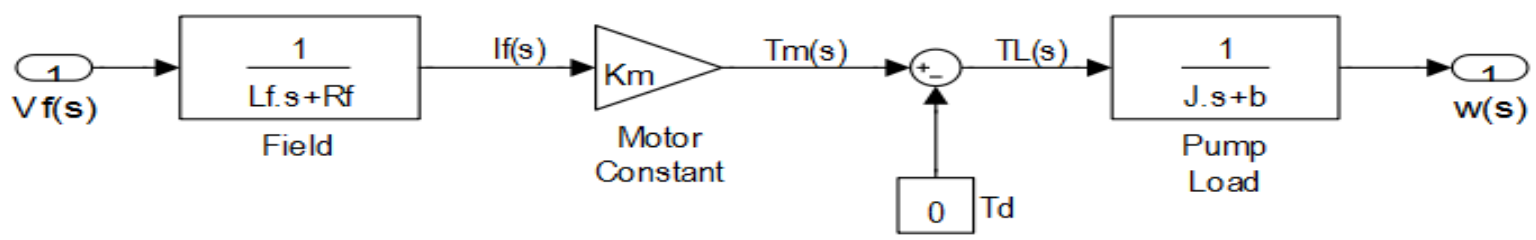

Figure 3: Block Diagram of Field-Controlled DC Motor for Driving Lube Oil Pump

Taking Laplace transform of equation (10), rearranging equation 6 and combining these, the result is written from [3] as:

$$
\frac{K_{m} V_{f}(s)}{R_{f}+L_{f} s}=J \omega(s)+b \omega(s)+T_{d}
$$

Therefore the transfer function of the motor-pump load combination, with $T_{d}=0$ is:

$$
\frac{\omega(s)}{V_{f}(s)}=\frac{K_{m} / J L_{f}}{s^{2}+\left[\left(R_{f} J+L_{f} b\right) / J L_{f}\right] s+R_{f} b / J L_{f}}
$$

The block diagram of the field-controlled DC motor is shown in Figure 3.

\subsubsection{Estimation of Lube Oil Pump Inertia $J_{p}$}

The pump torque was dependent on the inertia of the pump impeller directly coupled to the motor shaft and the angular speed of the drive shaft. Hence, it was necessary to accurately determine this parameter as the motor torque requirement is greatly associated with it. However, the inertia of a pump impeller is its resistance to changes in angular velocity as it rotates about its shaft. This accounts for the rotational mass of the impeller and is typically $10-15 \%$ of the motor inertia. Accurate values of the pump impeller inertia are usually available from the vendor and can be used where possible [1].During transient analysis it is often most conservative to underestimate the pump moment of inertia, particularly for fluids with high vapour pressures. Pumps with a lower moment of inertia will spin down faster, more abruptly slowing the fluid at the pump outlet while fluid further down the pipe line continues to flow due to momentum. While it is advisable to always obtain inertia data from vendors, it is not always readily available. In these circumstances the pump moment of inertia was estimated using equation 13.

$$
J_{p}=1.5 \times 10^{7} \times\left(\frac{P}{N^{3}}\right)^{0.9556}
$$

Where, $\mathrm{P}$ is pump power (kW) and $N$ is pump speed (rpm).

The shaft power of the pump was calculated from equation 14 as shown below

$$
P=\frac{\rho \times Q \times h \times g}{\Omega \times 3.6 \times 10^{6}}
$$

Where $\rho$ is density of lube oil $\left(\mathrm{kg} / \mathrm{m}^{3}\right), Q$ is the volumetric flow rate $\left(\mathrm{m}^{3} / \mathrm{s}\right), h$ is differential head of the pump (m), $g$ is acceleration due to gravity $g=9.81 \mathrm{~ms}^{-2}$ and $\Omega$ is the pump efficiency.

Equations 13 and 14 were used to estimate the mass inertia of the pump impeller, depending on the parameter given by the pump manufacturer.

\subsubsection{Design and Modelling of Fuzzy Logic Controller}

The success of any designed FLC is based on heuristic and expert knowledge of the system that is to be controlled [9]. Typically, a fuzzy logic controller has at least two inputs and one output. A fuzzy inference system (FIS) maps given inputs to outputs using fuzzy logic membership functions. A membership function (MF) is a shape that defines how each point in the input space is mapped to a membership value (or degree of membership) between 0 and 1 . The input space is sometimes referred to as the universe of discourse which needs to be specified by the designer. There are two styles of FIS used in fuzzy logic controllers and these are Mamdani and Sugeno styles. Mamdani's fuzzy inference method is the most commonly used methodology and can make do with different membership functions in its inputs and outputs [10].

For this design, the input and output is defined as follows: since FLC requires at least two inputs and one output, the first input will be the speed error $(E)$ while the second is the changein error of the speed $(\Delta E)$. The DC motor shaft rotational speed is the output $(\omega)$, and the equations relating these are written in equations 15,16 and 17.

$$
\begin{gathered}
E(t)=\omega_{\text {ref }}(t)-\omega_{a c}(t) \\
\Delta E=E(t)-E(t-1) \\
\omega(t)=\omega(t)-\omega(t-1)
\end{gathered}
$$

where, $t$ is the time factor, $\omega_{a c}=1414 \mathrm{rpm}$ is the actual speed achieved by the motor, $\omega_{\text {ref }}=1450$ is the desired speed required by the lube oil pump to provide the optimum oil pressure for the turbine.

\subsubsection{Membership Function Definition and Rules Formulation}

However, one needs to define all the linguistic terms that would be used for specifying our membership functions MF. These terms formed the sets of antecedents and consequents in the fuzzy rule-based table which are 
employed in quantifying the input and output values or degree of membership in the fuzzy sets. Table 1 shows the linguistic term for MF.

There were two MF used for modelling the FLC, and these include the triangular and the trapezoidal. The membership functions types used for the DC motor of the lube oil pump has universe of discourse of $E, \Delta E$ and $\omega$ as $+/-36,+/-3.6$ and $0-225.63$ respectively. Table 2 now shows the initial rules formulated for this FLC design.

The rules were actually formed in fuzzy logic toolbox and translated into the table above. In Table 2, the grey coloured row and column represent the linguistic terms that constitute the antecedents of fuzzy rules with respect to the heuristic variables, speed error and change in speed error. The middle section of the table with a clear background is actually the consequents of the rules. The shapes of the membership functions used are presented in Figure 4. The triangular and trapezoidal membership functions are often used because these curves make it flexible and easy to represent the proposed ideas and facts of the model, and with less computational time requirement. Then in order to obtain the output of the FLC, the rotational speed of the motor (output fuzzy set) is defuzzified into crisp value using the centre of gravity method. Moreover, FIS mapped given inputs to outputs using fuzzy logic rules via the membership functions.

\subsubsection{Modelling and Simulation of Lube Oil Pump DC Motor and FLC}

The mathematical models of the lube oil pump DC motor and the fuzzy logic controller developed were simulated in MATLAB and Simulink environment. MATLAB as a high-level technical computing language and interactive environment was employed for algorithm development, modelling, simulation, data visualization and analysis.

Table 1: Membership Function Terms

\begin{tabular}{cc}
\hline MF Terms & Description \\
\hline NL & Negative Large \\
NM & Negative Medium \\
NS & Negative Small \\
Z & Zero \\
PS & Positive Small \\
PM & Positive Medium \\
PL & Positive Large \\
\hline
\end{tabular}

Table 2: Fuzzy-based Initial Rules

\begin{tabular}{|c|c|c|c|c|c|c|c|c|}
\hline & \multicolumn{8}{|c|}{ Speed Error $(E)$} \\
\hline & & $\mathrm{NL}$ & NM & $\mathrm{NS}$ & $\mathrm{Z}$ & PS & PM & $\overline{P L}$ \\
\hline & NL & $\mathrm{NL}$ & $\mathrm{NL}$ & $\mathrm{NL}$ & $\mathrm{NL}$ & NM & NS & $\mathrm{Z}$ \\
\hline & NM & $\mathrm{NL}$ & $\mathrm{NL}$ & $\mathrm{NL}$ & NM & NS & $\mathrm{Z}$ & PS \\
\hline & NS & $\mathrm{NL}$ & NL & NM & NS & $\mathrm{Z}$ & PS & PM \\
\hline \multirow{4}{*}{ Change $(\Delta E)$} & $\mathrm{Z}$ & $\mathrm{NL}$ & NM & NS & $\mathrm{Z}$ & PS & PM & PL \\
\hline & PS & NM & NS & $\mathrm{Z}$ & PS & PM & PL & PL \\
\hline & PM & NS & $\mathrm{Z}$ & PS & PM & PL & PL & PL \\
\hline & PL & $\mathrm{Z}$ & PS & PM & PL & PL & PL & PL \\
\hline
\end{tabular}

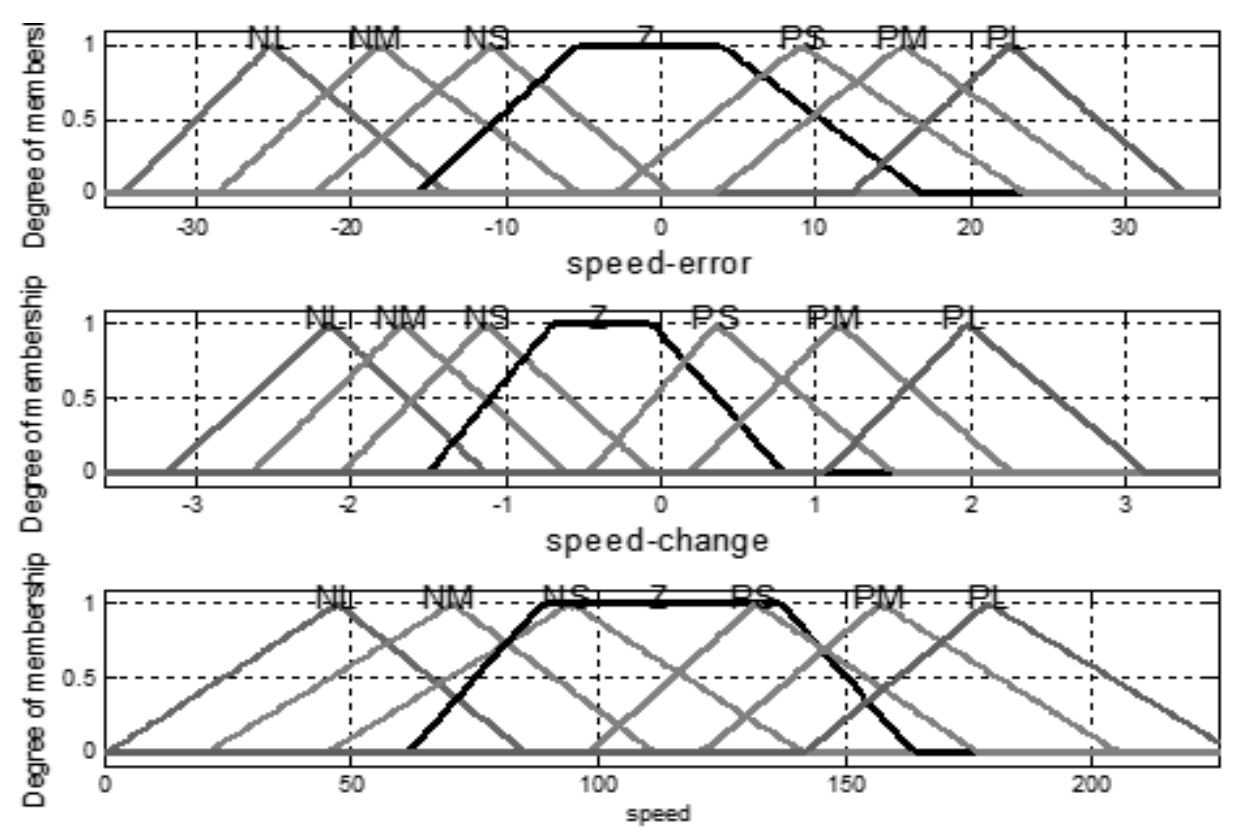

Figure 4: Initial Membership Functions for the FLC 
It essentially offers the platform on which the behaviour of the system could be investigated under different operating conditions.

\subsubsection{Modelling and Simulation of Lube Oil Pump DC Motor and Fuzzy Logic Controller.}

The mathematical models of the lube oil pump DC motor and the fuzzy logic controller were actually simulated in MATLAB and Simulink environment. In order to model the DC motor, its parameters are obtained from the case study industry using the Lube-Oil Pump Motor of the H25 Hitachi Turbine Generator at Bonny Oil and Gas Terminal. Appendix I shows the required parameters for the field-controlled DC motor while Appendix II shows the lube oil pump parameter for computing impeller inertia

Using equation (12), the lube oil pump motor was modelled in Simulink environment and shown in Figure 5. Before simulating the model for the speed response, the total inertia on the motor shaft must be computed. First, from Equations (13) and (14), the pump impeller inertia was calculated and substituted in Equation (9) to obtain the total inertia on the motor shaft. This was done by writing MATLAB code in a script which detailed all the parameters of the model. However, the final transfer function in equation (12) for the motor is evaluated and presented in equation (18).

$$
\frac{\omega(s)}{V_{f}(s)}=\frac{2018}{s^{2}+108.6 s+1499}
$$

\section{RESULTS AND ANALYSIS}

\subsection{Model Simulation Results}

The model was simulated for period of 1 second and the DC motor speed and angular position responses are depicted in Figures 6 and 7. The speed response showed that the motor attained an actual maximum speed of $\omega_{\mathrm{ac}}=1414 \mathrm{rpm}$. A very short settling time of $0.3 \mathrm{sec}$ is evident from the plot above. This speed $\omega_{\mathrm{ac}}=$ $1414 \mathrm{rpm}$ is lower than the optimum speed $\left(\omega_{\mathrm{op}}=\right.$ 1450rpm) needed to supply the required lubrication oil pressure to the turbine during idling.

Therefore, it would be necessary to model a controller to enable the optimal speed for the motor to be achieved. Also, figure 7below illustrates the angular position of the motor shaft in radians which is directly tied to the rotational speed of the motor. The angular position increases linearly with time and recorded an approximate value of $\theta=137 \mathrm{rad}$ in $1 \mathrm{sec}$. This implies a total angle of revolution of the shaft of $\theta=$ $8241 \operatorname{deg}$ which is about $\theta=23 \mathrm{rps}$. Hence, the motor shaft would certainly climb as high as $1414 \mathrm{rev}$ in $60 \mathrm{sec}$.

\subsection{Model Evaluation Criteria}

There are many performance indices used in control engineering design for evaluating how well a designed system would perform in practice. In this work, only time domain response indices are used. Figure 8 shows the response of the system to a standard test input. In computing the system step response, Simulink software first linearizes the nonlinear mathematical relationship in equation 18 about the input and output points of the model shown in Figure 5 .

The system has a rapid and smooth response to step input. The overshoot of $2.22 \times 10^{-14} \%$ indicated that the system step response is not chaotic. This is because the system has no complex poles and no zeros, a pointer to the fact that there are virtually no internal delays. Table 3 summarizes all the performance indices for the step response. The transient response disappears beyond the rise time of $0.139 \mathrm{sec}$ and finally gives way to the steadystate response at the settling time of $0.253 \mathrm{sec}$.

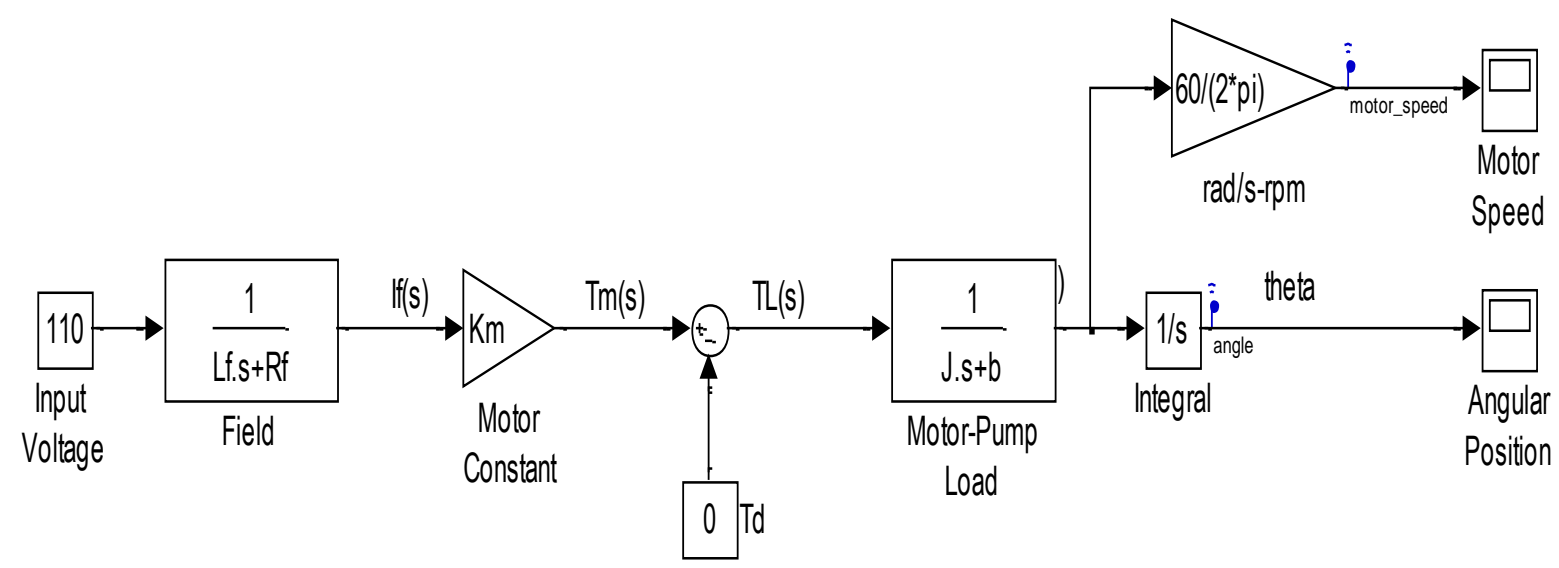

Figure 5: Simulink Model of Lube Oil Pump Field-Controlled DC Motor 


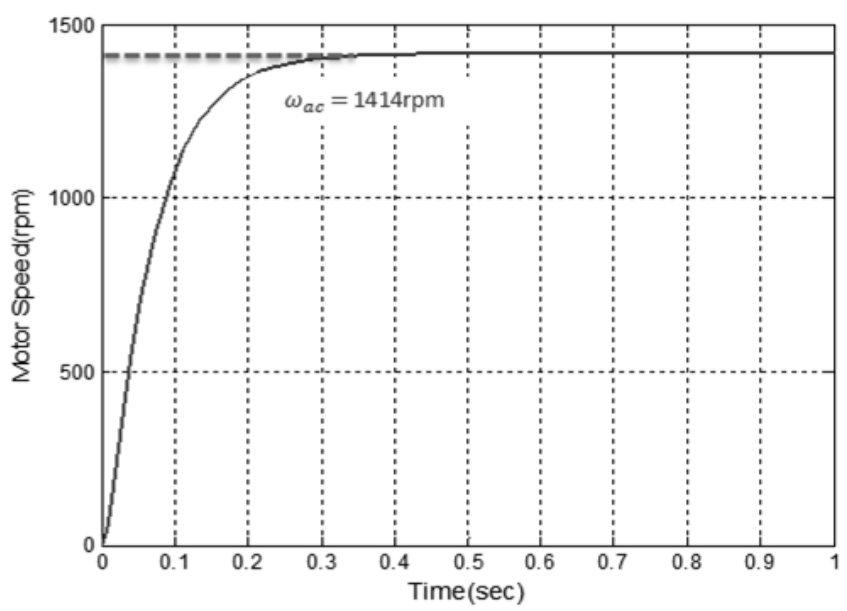

Figure 6: Speed Response of DC Motor for running an Emergency Lube Oil Pump in H25 Hitachi Gas Turbine Generator

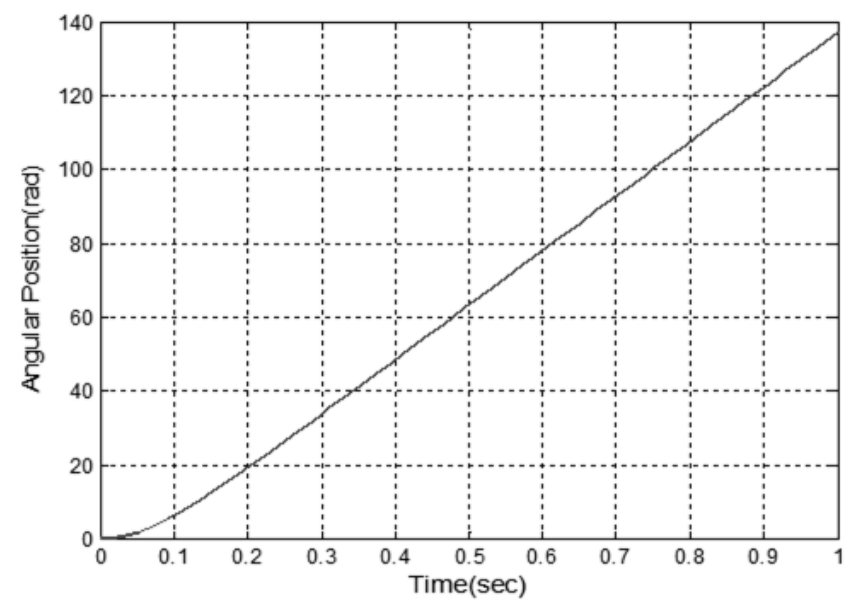

Figure 7: Angular Position Response of DC Motor for running an Emergency Lube Oil Pump in H25 Hitachi Gas

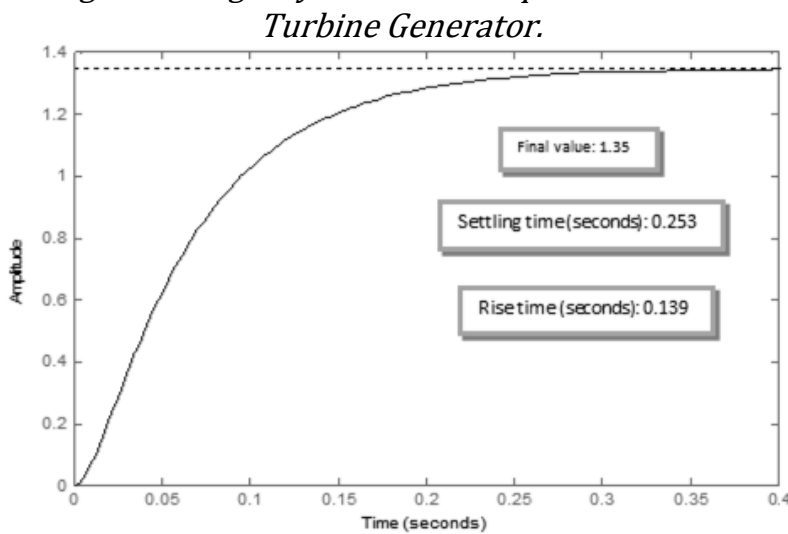

Figure 8: Response of DC Motor for running an Emergency Lube Oil Pump in H25 Hitachi Gas Turbine Generator

Overshoot and the settling time represent the degree of closeness of the step response to the desired response. The final peak value of the step response occurred at an amplitude of 1.34 in $0.4 \mathrm{sec}$. These low rise and peak times actually demonstrate how swift the system is to step input signals, and the optimality of the system dampness.
Table 3: Step Response Performance Analysis DC Motor for Lube Oil Pump

\begin{tabular}{ccc}
\hline Performance Indices & Values & Units \\
\hline Peak Amplitude & $\geq 1.34$ & - \\
Peak Time & $>0.4$ & $\mathrm{Sec}$ \\
Rise Time & 0.139 & $\mathrm{Sec}$ \\
Settling Time & 0.253 & $\mathrm{Sec}$ \\
Overshoot & $2.22 \times 10^{-14}$ & $\%$ \\
Steady State Error & $>0.34$ & - \\
\hline
\end{tabular}

The steady-state error is equally low at $>0.34$, and this means it is $>34 \%$. This can be driven low or zeroed whenthe FLC is introduced into the system.

\subsection{Speed Response of the DC Motor with the Fuzzy Logic Controller.}

The Simulink model of the FLC used for correcting the actual speed of the motor from $1414 \mathrm{rpm}$ to the desired speed of $1450 \mathrm{rpm}$ is shown in Figure 9. The content of the DC motor subsystem, if double clicked in Simulink environment, is exactly the same model in Figure 5. This FLC-DC motor model is simulated for a period of $1 \mathrm{sec}$ and speed response is shown in Figure 10.

The speed response indicated that the FLC controller is able to issue a control action which finally corrected motor speed to the required optimum speed of1450 rpm.

\subsection{FLC Model Adjustment and Performance Analysis}

Adjusting the shapes of the membership function can greatly enhance the performance of the FL controller. A common practice during FLC fine-tuning is to make the adjacent sides of the MF shapes or fuzzy set values to overlap one another by $25 \%$, thereby improving both efficiency and performance. In addition, if the areas of the membership functions that extend far away from the $\mathrm{Z}$ region are broadened, the response of the controller becomes faster. Also, performance improvement is accomplished by systematically reducing the weight of the fuzzy logic rules which is otherwise known as reduction in rules severity. The number of rules was reduced from 49 to 19 . After FLC model adjustment and rules reduction, the inputs and output MFs, and the nonlinear control surface is represented in Figures 11 and 12. Comparing Figure 4 with Figure 11, it can be seen that the shapes of the membership functions have been adjusted. 


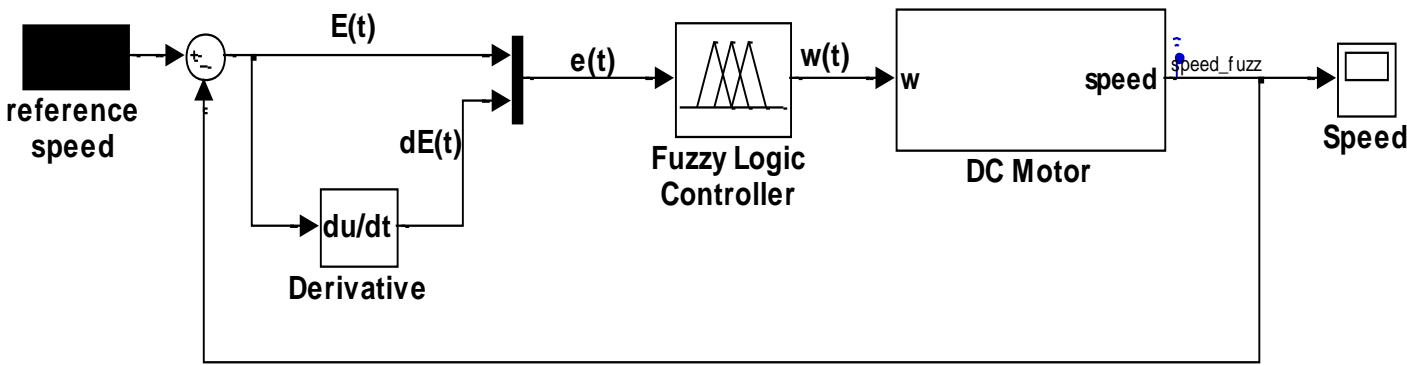

Figure 9: Simulink Model of FLC and DC Motor.

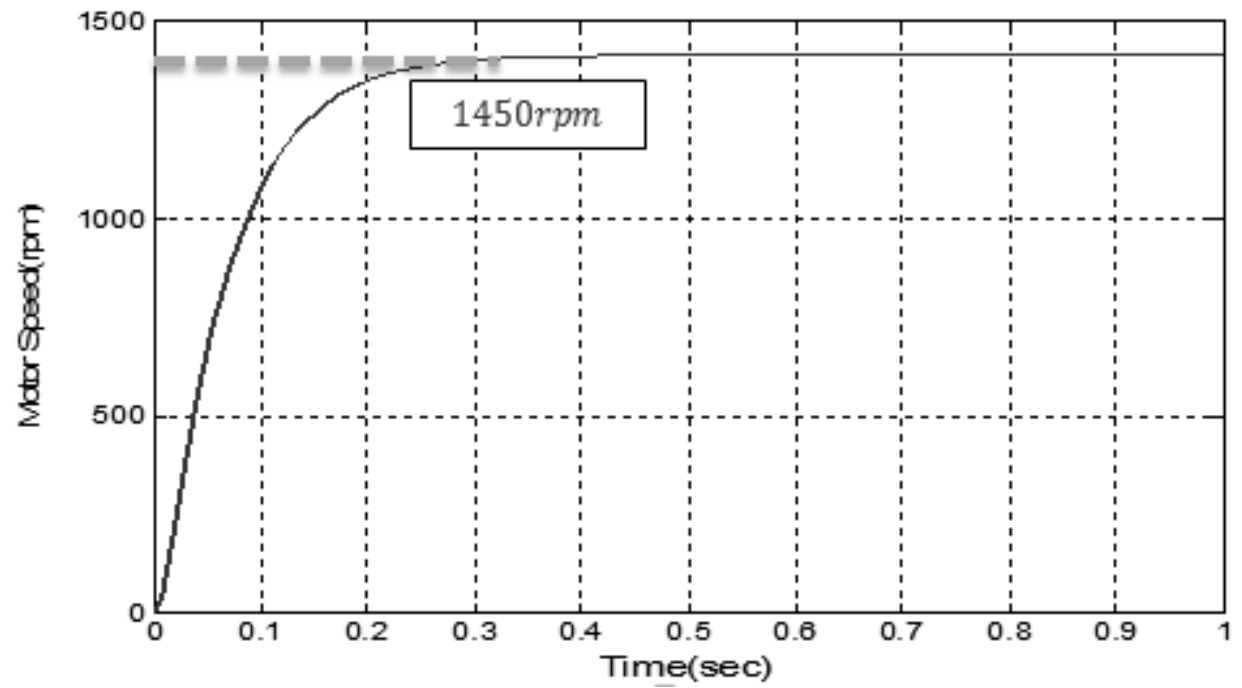

Figure 10: Speed Response of DC Motor with FLC for Running an Emergency Lube Oil Pump in H25 Hitachi Gas Turbine Generator
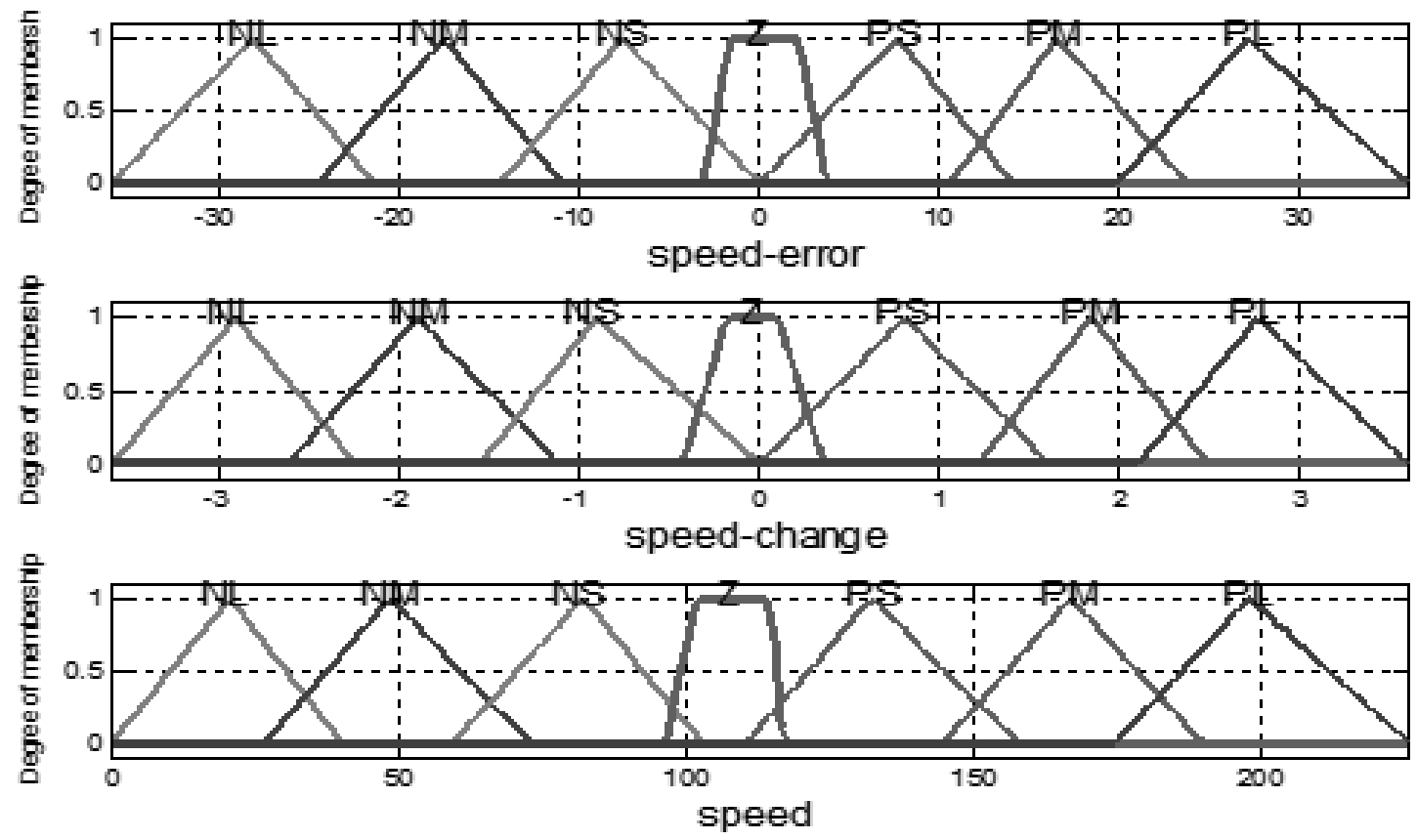

Figure 11: Adjusted Triangular and Trapezoidal inputs and Output Membership Functions. 


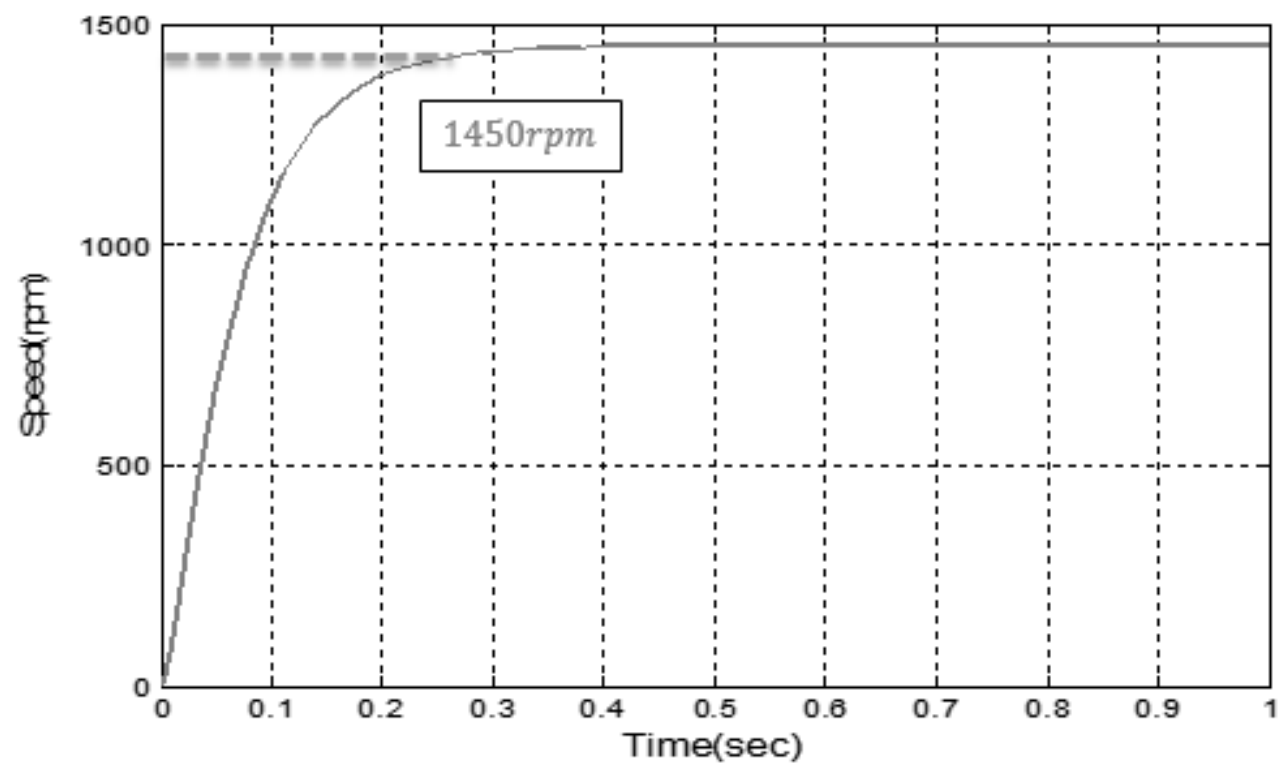

Figure 12: Speed Response of DC Motor with Adjusted FLC for Running an Emergency Lube Oil Pump in H25 Hitachi Gas Turbine Generator

The adjusted FLC was reintroduced into the Simulink model of the DC motor loop and simulated for a period of $1 \mathrm{sec}$. the speed response plot in figure 12 above shows that the controller still maintains the speed at $1450 \mathrm{rpm}$ but with a much faster response. Consequently, the model performance indices earlier described are equally affected as shown in Table 4.A linear model is first computed from the nonlinear Simulink model of the FLC before the linear response is plotted. During simulation, the software linearizes the portion of the model between specified linearization inputs and outputs, and plots the response of the linear system.

Table 4: Performance Indices of DC Motor with Adjusted FLC

\begin{tabular}{lcc}
\hline Performance Indices & Values & Units \\
\hline Peak Amplitude & 1450 & rmp \\
Peak Time & 1 & sec \\
Rise Time & 0.12 & sec \\
Settling Time & 0.20 & sec \\
Overshoot & 6 & $\%$ \\
Steady State Error & 0 & - \\
\hline
\end{tabular}

It is clear from Table 4 that there is an improvement in the performance of the DC motor and the fuzzy logic controller except for a slight increase in system overshoot. This is because FLC is inherently robust and nonlinear with elements of uncertainties in its structure.

\section{CONCLUSION}

The modelling of Fuzzy Logic Controller (FLC) for controlling the speed of a field-controlled DC motor of an emergency lube oil pump, during idling operation of a
5.5KW, H25 Hitachi Turbine Generator at Bonny Oil and Gas Terminal, has been presented. The results from the motor modelled and simulated indicated that based on industry parameters, the motor attained a maximum speed of $1414 \mathrm{rpm}$. However, the developed FLC was introduced into the control loop to correct the speed of the DC motor to the required operating speed of $1450 \mathrm{rpm}$ for the lube oil pump. The simulation results were obtained using MATLAB/Simulink. The results showed that the overshoot, settling time, peak time and control performance improved greatly by using fuzzy logic controller. Time domain performance indices such as peak time, rise time, settling time and steady state error showed that the FLC enabled the DC motor to perform faster and better when the shapes of the membership functions of the controller were adjusted accordingly.

\section{REFERENCES}

[1] Byington, C. S. "Intelligent Monitoring of Gas Turbine Engine Lubrication Systems", Association of Research Libraries, Vol. 98, Number 10, 1998, pp 2328.

[2] Marks, R. J. II (Ed.),."Fuzzy Logic Technology and Applications", IEEE Technology Update Series, Vol. 19, Number 26, 1994, pp 19-24.

[3] Chandra, R. and Kumar, M. "Speed Control of S.E.D.C. Motor by Using PI and Fuzzy Logic Controller", International Journal of Soft Computing and Engineering, Vol. 3, Number 2, 2013, pp 143153. 
[4] Guillaume, S. and Charnomordic, B. "Fuzzy Inference Systems: An Integrated Modelling Environment for Collaboration between Expert Knowledge and Data Using Fispro", Expert Systems with Applications, Vol. 39, Number 10, 2012, pp 8744-8755.

[5] Dorf. R. C. Electric Circuits, John Wiley and Sons, Paperback, New York, 1996

[6] Vas, P. V. and Druy, W. "Electrical Machine and Drives: Present and Future", $8^{\text {th }}$ Mediterranean Electro technical Conference, Vol. 1, Number 6,1996, pp. 404-408.

[7] Niasar, A. H., Moghbelli, H. and Vahedi, A. "Speed Control of a Brushless DC Motor Drive via Adaptive Neuro-Fuzzy Controller Based on Emotional Learning Algorithm", Proceedings of the Eighth International Conference on Electrical Machines and Systems. ICEMS,N anjing, China, 2005. Vol. 1, pp. 230-234, 27-29.

[8] Dorf, R. C. and Bishop, R. H. Modern Control Systems, Prentice Hall, Paperback, New York, 2001

[9] Kosko, B. Fuzzy Engineering, Prentice Hall, Paperback, New Jersey, 1997.

[10] Jurado, F. Ortega, F. M., Cano, A. and J Carpio, J.” Neuro-Fuzzy Controller For Gas Turbine in BiomassBased Electric Power Plant", Electric Power Systems Research, Vol. 60, Number 3, 2002, pp 115-119.
[11] (http://www.pall.com/images/Aerospace-DefenseMarine/aerospace engine lube systems chart1.jpg).

6. APPENDIX I: Lube Oil Pump DC Motor Parameters

\begin{tabular}{ccc}
\hline Parameter Name & Symbols & Values \\
\hline Power $(K W)$ & $P_{m}$ & 5.5 \\
Input Voltage $(V)$ & $V_{f}$ & 110 \\
Input Current $(A)$ & $I_{f}$ & 61.1 \\
Speed $(\mathrm{rpm})$ & $\omega_{r e f}$ & 1450 \\
Resistance $(\Omega)$ & $R_{f}$ & 1.8 \\
Inductance $(H)$ & $L_{f}$ & 0.0195 \\
Inertia $\left(\mathrm{kgm}^{2}\right)$ & $J_{m}$ & 0.0002215 \\
Torque Constant $(\mathrm{Nm} / \mathrm{A})$ & $K_{m}$ & 0.0128 \\
Viscous Damping & $b$ & 0.005283 \\
Coefficient $\left(\mathrm{kgm}^{2} / \mathrm{s}\right)$ & &
\end{tabular}

7. APPENDIX II: Oil Pump Parameter for Computing Impeller Inertia

\begin{tabular}{lcc}
\hline Parameter Name & Symbols & Values \\
\hline Pump efficiency (\%) & eff & 95 \\
Specific Speed $(\mathrm{rpm})$ & $N$ & 1450 \\
Density of Oil-SAE-50 $\left(\mathrm{kg} / \mathrm{m}^{3}\right)$ & $\rho$ & 890.8 \\
Differential head $(\mathrm{m})$ & $h$ & 5 \\
Acceleration due to gravity $\left(\mathrm{m} / \mathrm{s}^{2}\right)$ & $g$ & 9.81 \\
Volumetric flow rate $\left(\mathrm{m}^{3} / \mathrm{s}\right)$ & $Q$ & 0.5 \\
\hline
\end{tabular}

